\title{
Nanostructured Protective Coating Systems, Fireproof and Environmentally Friendly, Suitable for the Protection of Metallic Substrates
}

\author{
Andrea M. Pereyra, Guadalupe Canosa, and Carlos A. Giudice* \\ Universidad Tecnológica Nacional (UTN), Calle 60 y 124, (1900) La Plata, Argentina, and Centro de \\ Investigación y Desarrollo en Tecnología de Pinturas (CIDEPINT), Calle 52 e/121 y 122, (1900) La Plata, Argentina
}

\begin{abstract}
The aim of this study was to formulate, develop, and determine the behavior of nanostructured protective coating systems, fireproof and environmentally friendly, suitable for the protection of metallic substrates. The results allowed concluding that the di- and tripigmented formulations based on laminar zinc, either alone or mixed with nanozinc, showed an excellent corrosion resistance when a nanostructured self-cured inorganic silicate (high silica/alkali ratio) was selected as the film forming material. Coating systems included a sealer of low permeability, which was based on the same film forming material that primers and on laminar pigments. Intumescent coatings were manufactured and then applied on the sealer; in this study, two types of products in an aqueous single package were formulated. The anticorrosive capacity was evaluated in a salt spraying (fog) chamber and in a $100 \%$ relative humidity cabinet while the performance against the fire action was determined by estimating the limiting oxygen index in the LOI cabinet, the flame advance in an inclined tunnel, and, finally, the thermal conductivity in a UL 94 flame chamber; in the last test, the degree of intumescence was also assessed. The results showed an excellent ability for corrosion controlling and, in addition, a good performance against the fire action of some of the no pollutant coating systems designed.
\end{abstract}

\section{Introduction}

All materials of construction are deteriorated by the action of fire; although iron and steel are usually considered totally immune, they demonstrated in many cases that after thermal action as a product of a conflagration their mechanical properties are noticeably diminished according to the elevation of temperature: thus, for example, from 250 to $500{ }^{\circ} \mathrm{C}$, their mechanical resistance is reduced to $50 \%$ of the original value whereas up to $750{ }^{\circ} \mathrm{C}$ the diminution can reach $90 \% .^{1-8}$ On the basis of the previously mentioned information and in addition to the idea that iron and steel generally are susceptible to corrosion due to their high instability energy, it is necessary to design passive protective systems that simultaneously control the kinetics of the corrosive process to make it compatible with the estimated useful life of the structures and give resistance to them against to the action of fire with the purpose of allowing the evacuation of people in civil and industrial facilities. ${ }^{9-13}$

In the field of material protection, new approaches using nanoscale effects can be used to create coatings with significantly optimized or enhanced properties. Recent research on the incorporation of nanocomponents into conventional coatings has shown that nanosized materials can improve the physical and chemical properties of coating, i.e. it is now possible to formulate new kinds of coatings in which various nanomaterials are integrated into the microsystem in order to obtain unique and highly desirable properties. The final employment impact of nanoscience and nanotechnology in this discipline is seen in the development of new types of nanostructured systems with high technological importance. ${ }^{14,15}$

Considering that both zinc-rich and modified coatings perform better than other anticorrosive ones and since their success is based on the particular capacity to generate cathodic protection (zinc particle acts like a sacrifice anode) and a resistant barrier, ${ }^{16,25}$ anticorrosive primers are frequently based on metallic zinc and on several film forming materials. Coating

* To whom correspondence should be addressed. E-mail address: cagiudice@yahoo.com. systems can include a sealer of low permeability, which is usually based on a compatible film forming material and on laminar pigments.

To ensure effective protection against fire, an intumescent coating is selected as the top coat. This type of coating provides the thermal insulation to steel structures and other substrates: the dried films, under the action of heat, first soften and then swell due to internal release of combustible gases that remain in part retained, reaching a thickness of more than 100 times the original.

According to the above-mentioned information, the aim of this study was to formulate, develop, and determine the behavior of multilayer nanostructured coating systems, fireproof and environmentally friendly, suitable for the protection of metallic substrates.

\section{Materials and Methods}

2.1. Primer Formulation and Manufacture. In this paper, primers were formulated based on laminar zinc $(10.5 \mu \mathrm{m}$ average diameter; $99.5 \%$ purity in weigh; Figure 1) either alone or mixed with nanozinc (35 nm average diameter; 99.8\% purity in weigh) as the inhibiting pigment (laminar shape in series A; mixture of laminar zinc and of nanozinc, 90/10 ratio v/v, in series B), calcium silicate (12.1 $\mu \mathrm{m}$ average diameter) as the spacer of zinc particles, and eventually zinc hydroxiphosphite (3.0 $\mu \mathrm{m}$ average diameter) as the complementary inhibiting pigment. A nanostructured self-cured inorganic silicate was manufactured as a film forming material; ${ }^{26-32}$ it was prepared starting from a commercial sodium silicate solution (3.0/1.0 silica/alkali molar ratio) in an aqueous solution at $30 \% \mathrm{w} / \mathrm{w}$ and a colloidal silica solution of nanodimensions also at $30 \%$ w/w $\left(0.32 \%\right.$ sodium oxide content; $2.31 \mathrm{~g} \cdot \mathrm{cm}^{-3}$ density); the final silica/alkali molar ratio was 5.5/1.0.

The considered values of pigment volume concentration (PVC) were selected starting from the critical values (CPVC); these were estimated in the corrosion test (salt spraying chamber, Figure 1) and in the measures of permeability carried out on 


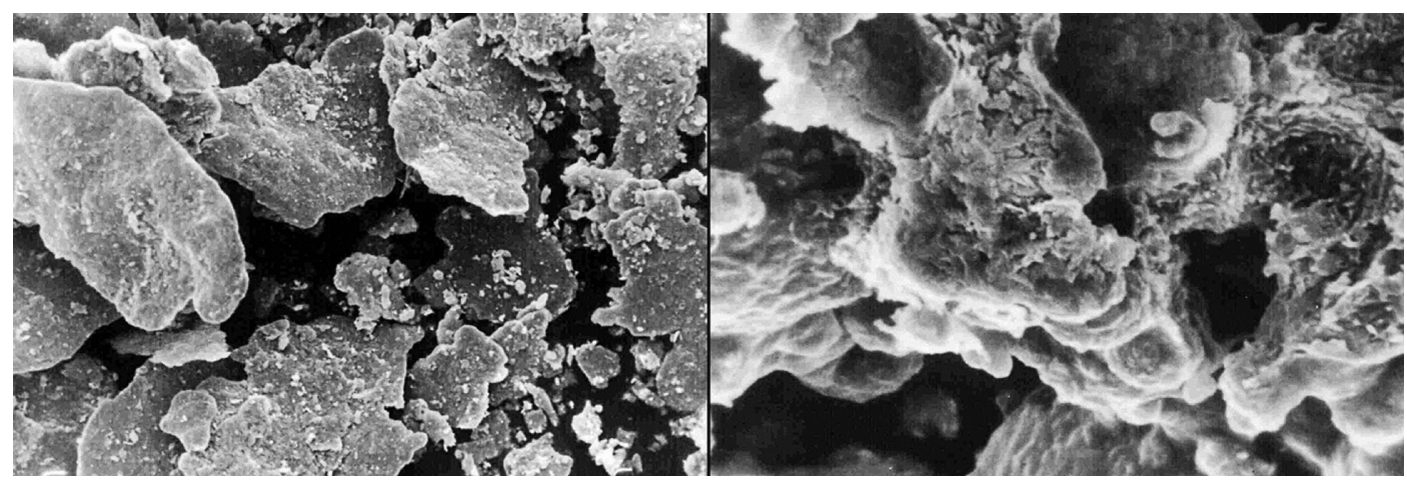

Figure 1. (left) Lamellar zinc dust alone. (right) Primer II.1, series B (laminar zinc/nanozinc (90/10 ratio v/v) after $1500 \mathrm{~h}$ of exposition in the salt spraying (fog) chamber (scanning electron microscopy (SEM), 7500×).

Table 1. Pigment Composition of Primers

\begin{tabular}{|c|c|c|c|}
\hline sample & $\begin{array}{c}\text { metallic pigment }{ }^{a} / \\
\text { extender/inhibitor ratio } \\
(\mathrm{v} / \mathrm{v})\end{array}$ & PVC, \% & CPVC, $\%$ \\
\hline I.1 & $80.0 / 20.0 / 0.0$ & 47.5 & $46 / 48$ \\
\hline I. 2 & $80.0 / 20.0 / 0.0$ & 45.0 & $46 / 48$ \\
\hline I. 3 & $80.0 / 20.0 / 0.0$ & 42.5 & $46 / 48$ \\
\hline I.4 & $80.0 / 20.0 / 0.0$ & 40.0 & $46 / 48$ \\
\hline II.1 & $65.0 / 25.0 / 10.0$ & 45.0 & $44 / 46$ \\
\hline II. 2 & $65.0 / 25.0 / 10.0$ & 42.5 & $44 / 46$ \\
\hline II. 3 & $65.0 / 25.0 / 10.0$ & 40.0 & $44 / 46$ \\
\hline II.4 & $65.0 / 25.0 / 10.0$ & 37.5 & $44 / 46$ \\
\hline
\end{tabular}

${ }^{a}$ Metallic pigment: series A, laminar zinc (100\%); series B, laminar zinc/nanozinc ( $90 / 10$ ratio $\mathrm{v} / \mathrm{v})$.

free films (75/80 $\mu \mathrm{m}$ dry film thickness) by applying the Gardner method. ${ }^{33}$ Values of PVC ranged from $42.5 \%$ to $50.0 \%$ (CPVC was estimated in 50/52\% for the formulations with zinc/extender and in $48 / 50 \%$ for tripigmented compositions); the variation between consecutive samples was $2.5 \%$, Table 1 .

Compositions were prepared in double packages with the purpose of avoiding the reaction between the metallic zinc and the water which would lead to the formation of hydrogen gas in the can. Consequently, previous to the application of primers and in a high speed mixer, the laminar zinc was dispersed; ${ }^{34-36}$ then, according with the formulation, zinc nanopowder was incorporated.

2.2. Sealer Formulation and Manufacture. In this case, the above-mentioned sodium silicate solution (silica/alkali 5.5/ 1.0 molar ratio) was used as a film forming material. With respect to pigmentation, micaceous iron oxide $\left(\mathrm{Fe}_{2} \mathrm{O}_{3} ; 16.5 \mu \mathrm{m}\right.$ average diameter; $87.2 \%$ purity in weight) and mica $\left(3 \mathrm{Al}_{2} \mathrm{O}_{3} \cdot \mathrm{K}_{2} \mathrm{O} \cdot 6 \mathrm{SiO}_{2} \cdot 2 \mathrm{H}_{2} \mathrm{O} ; 10.2 \mu \mathrm{m}\right.$ average diameter $)$, in a $50 / 50$ ratio $\mathrm{v} / \mathrm{v}$, were selected. The quantitative relationship between the pigment and the binder, expressed in terms of PVC, was $25.0 \%$ with the purpose of designing a film of low permeability to oxygen, water, and water vapor. ${ }^{37,38}$

The manufacture of sealer $\mathrm{S}$ involved, in one first stage, the dispersion of extender (mica) in the vehicle. Although the micaceous iron oxide displays a high chemical inertia, with the purpose of giving to the system prolonged stability in the package, the incorporation of this pigment was performed previous to the application of sealer.

The dispersion time was fit, according to the operative conditions of the equipment, with the purpose of reaching the mean diameter specified of the micaceous iron oxide particles; the determination was microscopically made. ${ }^{37,38}$

2.3. Intumescent Coating Formulation and Manufacture. To ensure effective protection against fire, the top coats selected were two intumescent coatings. ${ }^{39-43}$ Between the active pig- ments, pentaerythritol was used as a supplier of carbon (water solubility at $20{ }^{\circ} \mathrm{C}, 6.05 \mathrm{~g} / 100 \mathrm{~mL}$ ), ammonium polyphosphate as a catalyzing agent (white powder; $30.2 \%$ phosphorus and $14.5 \%$ nitrogen; low water solubility at $20{ }^{\circ} \mathrm{C}, 0.18 \mathrm{~g} / 100 \mathrm{~mL}$ ) and melamine as a gas generator (decomposition temperature, approximately $130{ }^{\circ} \mathrm{C}$; water solubility at $20{ }^{\circ} \mathrm{C}, 0.32 \mathrm{~g} / 100$ $\mathrm{mL})$.

In this paper, trihydrated alumina (aspect, granulated crystalline powder; $0.65 \mu \mathrm{m}$ average diameter; loss of weight in burning at $800{ }^{\circ} \mathrm{C}$, about $35.5 \% \mathrm{w} / \mathrm{w}$ ) and well-dispersed magnesium hydroxide nanopowder $(97.5 \% \mathrm{MgO}$ purity w/w; $78 \mathrm{~nm}$ average diameter; loss of weight in burning at $800{ }^{\circ} \mathrm{C}$, about $15 \% \mathrm{w} / \mathrm{w}$ ) were used as flame retardants pigments; both inorganic compounds contain an important percentage of hydration water. In addition, rutile titanium dioxide (aspect, very fine white powder; $0.25 \mu \mathrm{m}$ average diameter) was used as an opaque pigment.

Two thermoplastic materials were selected as binders: a pure acrylic latex (copolymer of methyl methacrylate and of normal butyl acrylate; minimum temperature of film formation, $13{ }^{\circ} \mathrm{C}$; water absorption after $24 \mathrm{~h}$ immersion, $12 \% \mathrm{w} / \mathrm{w}$ ) modified with nanosilica (acrylic latex/nanosilica solution ratio, 3/1 solids in volume) and a styrenated acrylic latex as reference (copolymer of the normal butyl acrylate and of styrene; minimum temperature of film formation, $20{ }^{\circ} \mathrm{C}$; water absorption after $24 \mathrm{~h}$ immersion, $8 \% \mathrm{w} / \mathrm{w}$ ); in both cases, the solid concentration in weight was of $50 \% .^{44}$

For the present experiment, although in one case the latex was used in conjunction with nanosilica, it was decided to formulate both intumescent coatings with $75 \%$ PVC that is approximately a $15 \%$ superior to the critical value $;^{45}$ the values of the CPVC were also estimated in a previous way. ${ }^{33}$ This last one is based on fires which have a major effect on the interiors of civil and industrial workplaces. The formulation of intumescent coatings is indicated in Table 2.

The manufacture was carried out in a discontinuous mill of high-speed stirring provided by one double jacket to control the system temperature during the pigment dispersion.

2.4. Preparation of Panels. The identification of the test panels is shown in Table 3. The metallic substrates (SAE 1010 steel plates) displayed an initial degree A; they were previously degreased with solvent in the vapor phase and then sanded to the degree Sa 2 1/2 (SIS specification 0559 00/67; maximum roughness $\left.R_{\mathrm{m}}, 35 \mu \mathrm{m}\right)$.

All the panels were initially protected with formulated primers. The application of primers was performed in only one layer $(75 / 80 \mu \mathrm{m}$ dry film thickness); in all cases, the panels were prepared in duplicate and stored for 7 days at $20 \pm 2{ }^{\circ} \mathrm{C}$. The sealer application was carried out in a single layer, with a 
Table 2. Composition of Fire-Retardant Coatings ${ }^{a}$

\begin{tabular}{lc}
\hline \multicolumn{1}{c}{ components } & percent, v/v \\
\hline distilled water & 47.1 \\
potassium tripolyphosphate & 0.5 \\
bactericides and fungicides & 0.5 \\
nanoclay & 2.0 \\
ammonium polyphosphate & 25.0 \\
pentaerythritol & 9.1 \\
melamine & 8.1 \\
titanium dioxide, rutile & 3.7 \\
magnesium hydroxide nanopowder & 2.0 \\
trihydrated alumina micronized powder & 2.0 \\
film forming material (solids) & (s)
\end{tabular}

${ }^{a}$ Samples were formulated with $75.0 \%$ PVC. ${ }^{b} \mathrm{RI}$, fire-retardant coating based on styrenated acrylic emulsion; RII, fire-retardant coating based on pure acrylic emulsion modified with nanosilica solution.

Table 3. Panel Identification, Series $A$ and $\mathrm{B}^{a}$

\begin{tabular}{|c|c|}
\hline panel & coating system $^{b}$ \\
\hline A.1/B.1 & $\mathrm{I} .1+\mathrm{S}+\mathrm{RI}$ \\
\hline A.2/B. 2 & $\mathrm{I} .1+\mathrm{S}+\mathrm{RII}$ \\
\hline A. $3 /$ B. 3 & $\mathrm{I} .2+\mathrm{S}+\mathrm{RI}$ \\
\hline A. $4 /$ B. 4 & $\mathrm{I} .2+\mathrm{S}+\mathrm{RII}$ \\
\hline A.5/B.5 & $\mathrm{I} .3+\mathrm{S}+\mathrm{RI}$ \\
\hline A.6/B.6 & $\mathrm{I} .3+\mathrm{S}+\mathrm{RII}$ \\
\hline A.7/B.7 & $\mathrm{I} .4+\mathrm{S}+\mathrm{RI}$ \\
\hline A. $8 /$ B. 8 & $\mathrm{I} .4+\mathrm{S}+\mathrm{RII}$ \\
\hline A.9/B.9 & II. $1+\mathrm{S}+\mathrm{RI}$ \\
\hline A.10/B.10 & II. $1+\mathrm{S}+\mathrm{RII}$ \\
\hline A.11/B.11 & $\mathrm{II} .2+\mathrm{S}+\mathrm{RI}$ \\
\hline A.12/B.12 & II. $2+\mathrm{S}+\mathrm{RII}$ \\
\hline A.13/B.13 & $\mathrm{II} .3+\mathrm{S}+\mathrm{RI}$ \\
\hline A.14/B.14 & II. $3+\mathrm{S}+\mathrm{RII}$ \\
\hline A. $15 /$ B. 15 & II. $4+\mathrm{S}+\mathrm{RI}$ \\
\hline A.16/B.16 & II.4 + S + RII \\
\hline
\end{tabular}

${ }^{a}$ Series A, primers with laminar zinc; series B, metallic zinc formed by a mixture of laminar zinc and nanozinc, 90/10 ratio v/v. ${ }^{b} \mathrm{RI}$, fire-retardant coating based on styrenated acrylic emulsion; RII, fire-retardant coating based on pure acrylic emulsion modified with nanosilica solution.

dry film thickness between $45 / 50 \mu \mathrm{m}$; the surface tension of this coating was properly adjusted with the purpose of avoiding the phenomenon of bubbling. At the end of this stage, the test panels remained in the laboratory environment for 7 days to complete the drying and the curing of the sealer film.

Finally, intumescent coatings were applied (three layers, 280-300 $\mu \mathrm{m}$ dry film thickness); the interval between layers was $48 \mathrm{~h}$. In all cases, and with the purpose of assuring the curing of films, the test panels were kept in controlled laboratory conditions for 7 days.

2.5. Laboratory Tests. The standardized procedures included tests in a salt spraying (fog) chamber (ASTM B 117) and 100\% relative humidity cabinet (ASTM D 2247). The assessment of the behaviors was performed by applying the ASTM D 1654 and ASTM D 714 standards to determine the degree of rusting, DR (general area of the panel, method B; $1500 \mathrm{~h}$ ), and the degree of blistering, DB (800 h), respectively.

With respect to the fire-retardant capacity, it was assessed in an inclined tunnel that corresponded to ASTM D 3806 standard (flame advance AL) and in a LOI cabinet under the guidelines of ASTM D 2863 standard (limiting oxygen index).

Meanwhile, for this experiment, a thermal conductivity CT test was specially designed. Panels of $200 \mathrm{~mm} \times 300 \mathrm{~mm} \times 3$ $\mathrm{mm}$ were prepared in similar way to the indicated for the abovementioned tests and were placed in the UL 94 flame chamber for avoiding airflows; the degree of intumescence (height in millimeters of the sponge layer) was assessed.

\section{Results and Discussion}

3.1. Film Forming Material Characterization. Morphology and size of associated particles of the colloidal silica solution of nanodimensions used for increasing the silica/alkali ratio at 5.5/1.0 were evaluated with SEM (scanning electron microscopy; Philips SEM 505, with analytical capacity through the microprobe system EDAX DX PRIME 10 for analysis qualitative/quantitative) while the specific area by using the BET method (the isotherms of nitrogen adsorption-desorption were measured at the temperature of liquid nitrogen of $77 \mathrm{~K}$ using a Micrometrics apparatus ASAP 2020).

In both cases, samples were heated at $300{ }^{\circ} \mathrm{C}$ for $2 \mathrm{~h}$ prior the measurements to produce the thermal desorption of the adsorbed organic substances used during manufacture since they may block active centers of the silica surface and therefore lower $\mathrm{N}_{2}$ adsorption takes place during estimation of the BET isotherm.

The analysis showed that the aggregates of individual particles of nanosilica have an effective diameter of $1022 \mathrm{~nm}$ (SEM) and the specific area displayed a value of $216 \mathrm{~m}^{2} \cdot \mathrm{g}^{-1}$ (BET). The $6 / d \rho$ ratio, indicating precisely the specific area of particles, suggests that individual particles have a mean diameter $d$ of approximately $12 \mathrm{~nm}$.

The new system prepared with 5.5/1.0 molar ratio through the incorporation of nanosilica in the commercial alkaline silicate solution showed the following characteristics at $20^{\circ} \mathrm{C}$ : density, $20.0{ }^{\circ} \mathrm{Be}$; viscosity, $76.8 \mathrm{cP}$; and $\mathrm{pH}, 10.3$.

The formation of inorganic polymer by acid silicification starting from soluble silicates and zinc cation to provide water insolubility (several water-soluble salts of above-mentioned cation were added to the soluble silicate solutions) indicated a quick formation of gel at the interface followed by propagation of the reaction into the aqueous phase. Then, a coagulated mass separated out.

Unpublished previous experiments carried out for the authors showed that larger ions and those with higher valence are held more strongly in the network; the relative size and charge of the ions influence the solubility of inorganic polymer generated by silicification.

The inorganic matrix polymer was characterized by applying $\mathrm{X}$-ray (the diffraction pattern of each sample in a glass holder was obtained at room temperature with $\mathrm{Cu} K$ radiation in a Philips 3020 diffractometer); diffraction intensities were measured at small angles between $0.6^{\circ}$ and $4.0^{\circ}$ with a step of $0.02^{\circ}$ for $10 \mathrm{~s}$ per point.

The XRD studies showed an interatomic distance between Si and $\mathrm{O}$ about $1.62 \AA$, and besides that, each oxygen is linked to two silicon atoms or to one silicon and one metal atom. The structure of glasses has a $\mathrm{Si}$ and $\mathrm{O}$ random arrangement with cations placed into holes in the network.

3.2. Coatings Systems Behavior. The factorial design for series $\mathrm{A}$ and $\mathrm{B}$ included 1 alkaline silicate (primer) $\times 2$ pigmentations (primer) $\times 4$ PVC values (primer) $\times 1$ sealer $\times$ 2 intumescent coatings; therefore, the design led to a total of 16 anticorrosive/fireproofing systems for both series A and B.

To study the variables considered (main effects), a statistical interpretation was carried out. First, the variance was calculated, and later, the Fisher F test was carried out. The results indicated that all the mentioned variables displayed an important influence on the performance of the protective systems.

Results of series A and B corresponding to DR, degree of rusting; DB, degree of blistering; LOI, limiting oxygen index; AL, flame advance, and CT, thermal conductivity of anticorrosivefire retardant coating systems are shown respectively in Tables 4 and 5. 
Table 4. Results of Series A (Anticorrosive-Fire Retardant Coating Systems) ${ }^{a}$

\begin{tabular}{cclcrc}
\hline sample & DR & DB & LOI, $\%$ & AL, mm & CT, ${ }^{\circ} \mathrm{C}$ \\
\hline A.1 & 7 & 9-M & 39 & 22 & 203 \\
A.2 & 7 & 8-F & 52 & 7 & 174 \\
A.3 & 8 & $8-M$ & 40 & 23 & 201 \\
A.4 & 7 & $8-M$ & 48 & 8 & 177 \\
A.5 & 7 & $8-M$ & 42 & 20 & 201 \\
A.6 & 6 & $8-M$ & 46 & 6 & 173 \\
A.7 & 7 & $7-M$ & 44 & 19 & 199 \\
A.8 & 4 & $8-M$ & 48 & 7 & 175 \\
A.9 & 8 & $8-F$ & 42 & 20 & 202 \\
A.10 & 8 & 9-F & 50 & 8 & 177 \\
A.11 & 8 & 8-F & 45 & 21 & 203 \\
A.12 & 7 & 8-F & 48 & 6 & 173 \\
A.13 & 7 & 8-M & 42 & 22 & 200 \\
A.14 & 7 & 8-F & 50 & 7 & 175 \\
A.15 & 7 & 8-M & 43 & 21 & 199 \\
A.16 & 7 & 7-M & 46 & 7 & 176
\end{tabular}

${ }^{a} \mathrm{DR}$, degree of rusting; DB, degree of blistering; LOI, limiting oxygen index; AL, flame advance; CT, thermal conductivity.

Table 5. Results of Series B (Anticorrosive-Fire Retardant Coating Systems $)^{a}$

\begin{tabular}{lrlrrr}
\hline sample & DR & DB & LOI, $\%$ & AL, mm & CT, ${ }^{\circ} \mathrm{C}$ \\
\hline B.1 & 8 & $9-\mathrm{F}$ & 42 & 24 & 196 \\
B.2 & 8 & $9-\mathrm{F}$ & 48 & 5 & 180 \\
B.3 & 7 & $8-\mathrm{F}$ & 44 & 22 & 193 \\
B.4 & 8 & $9-\mathrm{F}$ & 49 & 5 & 182 \\
B.5 & 7 & $8-\mathrm{F}$ & 40 & 25 & 193 \\
B.6 & 8 & $8-\mathrm{F}$ & 47 & 4 & 179 \\
B.7 & 8 & $8-\mathrm{M}$ & 41 & 21 & 198 \\
B.8 & 8 & $8-\mathrm{M}$ & 46 & 6 & 181 \\
B.9 & 10 & 10 & 43 & 23 & 195 \\
B.10 & 10 & 10 & 50 & 6 & 184 \\
B.11 & 10 & $9-\mathrm{F}$ & 40 & 23 & 197 \\
B.12 & 10 & 10 & 48 & 5 & 180 \\
B.13 & 10 & $9-\mathrm{F}$ & 44 & 22 & 193 \\
B.14 & 9 & 10 & 47 & 4 & 179 \\
B.15 & 9 & 10 & 42 & 24 & 195 \\
B.16 & 9 & $9-\mathrm{F}$ & 47 & 5 & 183
\end{tabular}

${ }^{a} \mathrm{DR}$, degree of rusting; DB, degree of blistering; LOI, limiting oxygen index; AL, flame advance; $\mathrm{CT}$, thermal conductivity.

3.2.1. Anticorrosive Performance. With the purpose of establishing the efficiency of each protective system from an anticorrosive point of view, the values of the degree of rusting corresponding to the areas without cutting and of the degree of blistering were averaged. With respect to this last aspect, initially the mean value corresponding to the size and the frequency was calculated; to quantify the frequency, the following numerical values were assigned: no blisters, 10.0; $\mathrm{F}$ (few), 7.5; M (medium), 5.0; MD (medium dense), 2.5 and D (dense), 0.0.

The results are displayed in Table 6; the highest mean value indicates the best performance; the systems B.9 and B.10 showed the greatest anticorrosive capacity.

Figure 2 shows the degree of rusting in two coating systems after $1500 \mathrm{~h}$ exposition in the salt spray (fog) chamber, panel A.8 (4; corroded area, about $10 \%)$ and panel B.10 (10; practically without corrosion). On the other hand, Figure 3 shows the degree of blistering in coating systems after $800 \mathrm{~h}$ exposition in the $100 \%$ relative humidity cabinet, panel A.8 (8-M) and panel B.10 (10).

In addition, the results point out that the tripigmented primers (particularly samples A.9/B.9 to A.16/B.16) had a better performance than dipigmented ones, which means that the complementary inhibiting pigment exerted a strong influence on the anticorrosive capacity. Moreover, results of Table 6 allow concluding that series B showed better performance than series
Table 6. Statistical Results: Anticorrosive Performance of Coating Systems $^{a}$

\begin{tabular}{cccccccc}
\hline & \multicolumn{3}{c}{ series A } & & \multicolumn{3}{c}{ series B } \\
\cline { 2 - 3 } \cline { 6 - 7 } PVC, $\%$ & primers & AC & mean value & & primers & AC & mean value \\
\hline 47.5 & A.1/A.2 & 7.2 & 6.8 & & B.1/B.2 & 8.1 & 7.6 \\
45.0 & A.3/A.4 & 7.0 & & & B.3/B.4 & 7.7 & \\
42.5 & A.5/A.6 & 6.5 & & & B.5/B.6 & 7.6 & \\
40.0 & A.7/A.8 & 6.3 & & & B.7/B.8 & 7.2 & \\
45.0 & A.9/A.10 & 8.0 & 7.4 & & B.9/B.10 & 10.0 & 9.5 \\
42.5 & A.11/A.12 & 7.7 & & & B.11/B.12 & 9.6 & \\
40.0 & A.13/A.14 & 7.1 & & & B.13/B.14 & 9.3 & \\
37.5 & A.15/A.16 & 6.7 & & & B.15/B.16 & 9.1 &
\end{tabular}

${ }^{a} \mathrm{AC}$, anticorrosive capacity (mean value of degree of rusting and degree of blistering).

A, which means that the partial replacement of laminar zinc by nanozinc led to an increase of the efficiency.

Another additional conclusion after making the analysis of mentioned Table 6 was obtained by establishing the influence of the PVC of primers, through the calculation of the mean values of the resistance to the oxidation and the formation of blisters. It is observed that as the PVC diminishes the protective capacity decreases; this could be based on a reduced availability of metallic zinc in the dry film that shortens the service life and/or in one more reduced film permeability for being formulated far from the critical value.

However, it is appropriate to mention that even those primers with the smallest PVC value (approximately $24.4 \%$ zinc in volume on the dry film, samples B.15/B.16) showed good performance after aging for $1500 \mathrm{~h}$ in the salt spraying (fog) chamber and $800 \mathrm{~h}$ in the $100 \%$ relative humidity cabinet (mean value 9.1 .

3.2.2. Fireproofing Eficiency. With respect to the behavior against the fire action, numerical values were settled down for the different tests; they range from 0 to 10 . For example, for the limiting oxygen index, the values 0 and 10 were assigned for 16 and $\geq 50 \%$, respectively; for flame advance, the values 0 and 10 were assigned for 555 and $0 \mathrm{~mm}$, respectively; and finally for thermal conductivity, 0 and 10 were assigned for 500 and $\leq 200^{\circ} \mathrm{C}$, respectively. In all cases, intermediate values were considered (linear scales between the quoted extremes values). Later, the mean values of the realized tests were calculated, Table 7.

The determination of LOI index was carried out with a flow rate of $3.2 \mathrm{~cm} \cdot \mathrm{s}^{-1}$. Experimental results corresponding to both intumescent coatings showed a self-extinguishing capability since their limiting oxygen index was higher than that corresponding to the experimental accepted limit for this type of chamber LOI $28 \% .{ }^{46}$ As a consequence, this test did not allow to establish a strong influence of the formulation variables considered in this study since both intumescent coatings displayed a very good performance: 42 and $48 \%$ for RI (fireretardant coating based on styrenated acrylic emulsion) and RII (fire-retardant coating based on pure acrylic emulsion modified with nanosilica solution), respectively.

The equation $\mathrm{AL}=\mathrm{Ls}-\mathrm{La}$ allowed the calculation of the flame advance AL assessed in the inclined tunnel, where Ls and $\mathrm{La}$ are the averages of the three flame advances observed respectively on the coated panels and on a bare cement-asbestos panel selected as reference (distance due to the reflection of the flame, $55 \mathrm{~mm}$ ); the average of the three consecutive highest values of the flame advance was calculated, which were measured at intervals of $15 \mathrm{~s}$.

Although both intumescent coatings showed very good performance, results indicate a marked difference among the 


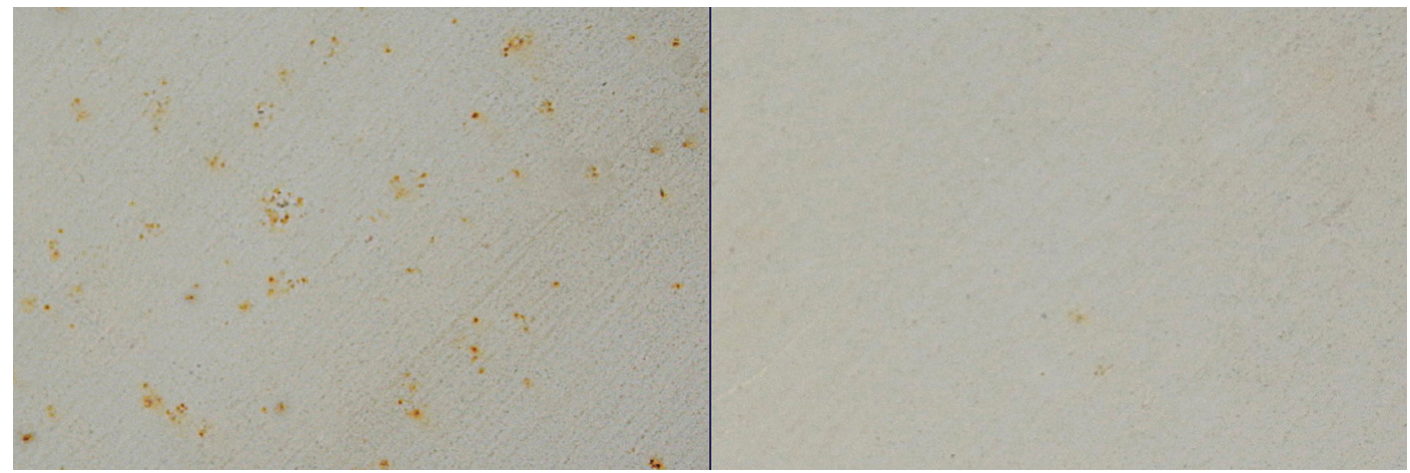

Figure 2. Degree of rusting in coating systems after 1500 h exposition in salt spray (fog) chamber: (left) panel A.8 (4; corroded area, about 10\%); (right) panel B.10 (10; practically without corrosion).

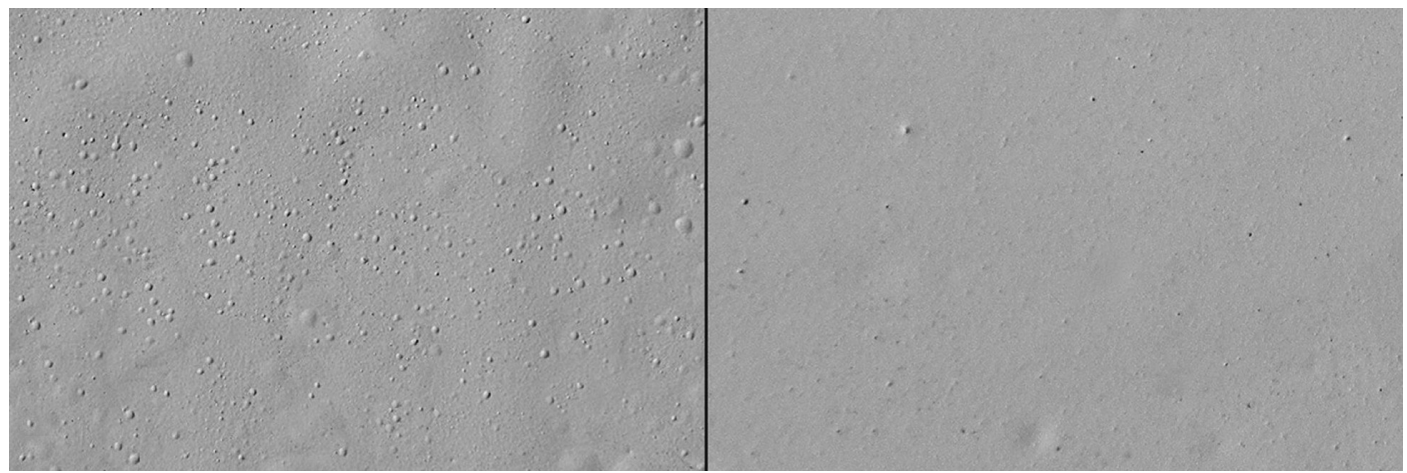

Figure 3. Degree of blistering in coating systems after $800 \mathrm{~h}$ exposition in $100 \%$ relative humidity cabinet: (left) panel A.8 (8-M) and (right) panel B.10 (10).

Table 7. Statistical Results: Performance against Fire of Coating Systems $^{a}$

\begin{tabular}{cccc}
\hline sample & LOI, \% & AL, mm & CT, ${ }^{\circ} \mathrm{C}$ \\
\hline RI & 42 & 22 & 198 \\
RII & 48 & 6 & 178 \\
R & & & 500
\end{tabular}

${ }^{a}$ LOI, limiting oxygen index; AL, flame advance; CT, thermal conductivity, and R, bare panel as reference.

efficiency of both intumescent coatings. Protective systems with RII as the finishing coat showed an enhanced performance with regard to the panels with RI: the average values were 6 and 22 $\mathrm{mm}$, respectively, beyond the flame advance registered on the panel of asbestos-cement.

As mentioned in the thermal conductivity test, panels protected with coatings systems under study were placed in the UL 94 flame chamber for avoiding airflows. A panel of bare steel, placed in a horizontal position, was selected as reference. A thermocouple as the measurement system was set to the face superior of the panel. A Bunsen burner, facing toward the face inferior to the panel, was located at a distance of $15 \mathrm{~mm}$; the intensity of the flame was regulated so as to reach on the other side a temperature of $500 \pm 5{ }^{\circ} \mathrm{C}$ after $25 \mathrm{~min}$. The coated panels were tested in a similar way, evaluating the temperature through the aforementioned thermocouple during the experiment.

The following criteria for qualifying as successful the formulated intumescent was applied: the temperature registered by the thermocouple at the back face of the painted panels should not exceed $200{ }^{\circ} \mathrm{C}$ during the test.

Results indicate that in both coatings the thermal insulation due to the charred coat formed after testing at the front of the panels led to temperatures at the back face inferior to the fixed limit: a maximum temperature of 181 and $195^{\circ} \mathrm{C}$ were reached at the back face after finishing the test respectively for coatings RII and RI which corroborates in this test a superior performance of RII with respect to RI.

The excellent thermal insulation could be explain since both coatings showed a significant intumescence and a quite uniform development; only in a few cases was a slight depression attributable to the flame pressure observed. The insulating layers remained firmly adhered to the substrate in all panels. Referring to the average height of the intumescence, values ranged between 22 and $25 \mathrm{~mm}$ for coating RI and between 28 and 30 $\mathrm{mm}$ for coating RII, Figure 4.

In addition, the effect of both endothermic filler should reduce the rate of temperature rise at the back face of metallic substrates: trihydrated alumina and well-dispersed magnesium hydroxide nanopowder counterbalanced the natural exothermic heat of decomposition produced during intumescence in the pyrolysis zone.

Finally, the analysis of results suggests that although both intumescent coatings showed very good performance, the coating based on pure acrylic emulsion modified with nanosilica displayed a noticeable major resistance against the fire action than the one with the styrenated acrylic emulsion in its composition, perhaps due to the presence of a binder partially mineralized in its composition.

3.3. Simultaneous Analysis of Anticorrosive and Fireproofing Eficiency. In the last stage of the statistical interpretation, all results were averaged to reflect simultaneously both the anticorrosive capacity and the resistance to the fire action. Thus, the mean values corresponding to the variables considered in this study (main effects) were obtained. In this case, the highest mean value indicates the best overall performance as well. 


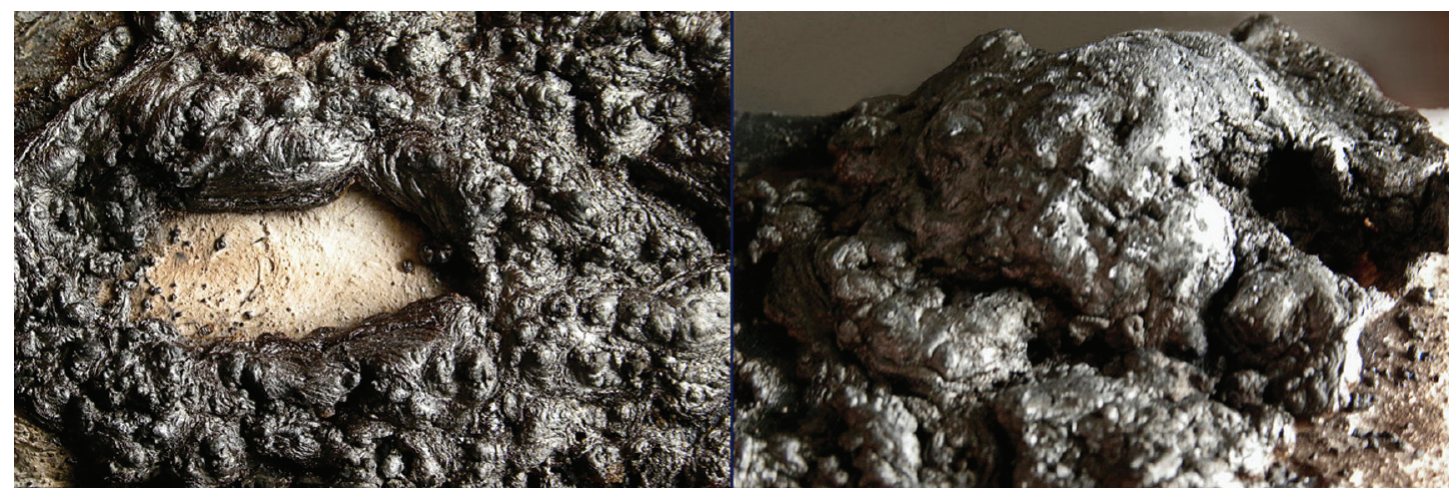

Figure 4. Performance of coating RII in the inclined tunnel: (left) slight depression attributable to the flame pressure; (right) between 28 and $30 \mathrm{~mm}$ height of the intumescence.

Table 8. General Statistical Results

\begin{tabular}{|c|c|c|}
\hline \multicolumn{3}{|c|}{ Influence of Pigmentation Type } \\
\hline pigment composition & $\begin{array}{l}\text { zinc/extender, } \\
80 / 20 \text { ratio v/v }\end{array}$ & $\begin{array}{c}\text { zinc/extendedor/inhibidor, } \\
65 / 25 / 10 \text { ratio } \\
\text { v/v }\end{array}$ \\
\hline series A (laminar zinc) & 6.8 & 7.4 \\
\hline series B (laminar zinc/nanozinc) & 7.6 & 9.5 \\
\hline general & 7.2 & 8.4 \\
\hline
\end{tabular}

\begin{tabular}{cc}
\hline \multicolumn{2}{c}{ Influence of Nanozinc in Primers } \\
\cline { 2 - 3 } series A & series B \\
\hline 7.1 & 8.6
\end{tabular}

\begin{tabular}{cc}
\hline Influence of Binder Type in Fire-Retardant Coating \\
\hline ptyrenated acrylic emulsion & $\begin{array}{c}\text { purylic emulsion modified with } \\
\text { nanosilica solution }\end{array}$
\end{tabular}

9.1 9.8

Results of Table 8, which includes simultaneous statistical analysis of all variables studied in the coating systems, support the conclusions reached from Table 6 in relation to the influence of the composition of the pigment and to those corresponding to Table 7 where the mean performance of intumescent coatings is included.

For example, Table 8 indicates that (i) with respect to the influence of the composition of pigment in primers, higher performance was achieved with a zinc/extender/inhibitor 65/ $25 / 10$ ratio $\mathrm{v} / \mathrm{v}$ (mean value 8.4 ) than that with the ratio zinc/ extender $80 / 20$ ratio v/v (mean value 7.2 ); (ii) in relation to the influence of nanozinc primers, series B (zinc laminar/nanozinc $90 / 10$ ratio $\mathrm{v} / \mathrm{v}$, mean value 8.6 ) performed in a markedly superior way to series A (100\% zinc laminar, mean value 7.1$)$; and finally (iii) concerning the influence of the binder type in intumescent coatings, the pure acrylic emulsion modified with nanosilica solution showed a better efficiency (mean value 9.8) than the styrenated acrylic emulsion (mean value 9.1).

In summary, the simultaneous analysis of all variables indicates that among the nanostructured protective coating systems studied, fireproof and environmentally friendly, the most suitable one for the protection of metallic substrates is that defined as B.10.

\section{General Conclusions}

The nanostructured materials offer interesting properties to study in the field of coating technology; in this paper, the following nanomaterials were successfully used:

- Nanosilica solution allowed the preparation of the efficient water-based primers and a sealer, with fireproof properties for steel protection, based on a nanostructured self-cured inorganic silicate (high silica/alkali ratio) as a film forming material.

- Well-dispersed nanozinc solution as the main inhibitor improved the anticorrosive capacity when it was mixed with laminar zinc to formulate primers based on nonpolluting pigments of the environment.

- Magnesium hydroxide nanopowder, in conjunction with microtrihydrated alumina, as flame-retardant pigments, and nanosilica solution as cobinder of pure acrylic resin led to the design of water-based intumescent coatings with very good performance against fire.

\section{Acknowledgment}

Are made to CONICET (Consejo Nacional de Investigaciones Científicas y Técnicas), UTN (Universidad Tecnológica Nacional), and CIC (Comisión de Investigaciones Científicas de la Provincia de Buenos Aires) from Argentina for their sponsorship for this research.

\section{Literature Cited}

(1) Saab, H.; Nethercot, D. Modelling steel frame behaviour under fire conditions. Eng. Struct. 1991, 13, 371.

(2) Wang, Y.; Moore, B. Steel frames in fire: analysis. Eng. Struct. 1995, 17,462 .

(3) Baileya, C. Development of computer software to simulate the structural behaviour of steel-framed buildings in fire. Comput. Struct. 1998, $67,421$.

(4) Dai, X.; Wang, C.; Bailey, C. Effects of partial fire protection on temperature developments in steel joints protected by intumescent coating. Fire Safety J. 2009, 44, 376.

(5) Bartholmai, M.; Schriever, R.; Schartel, B. Influence of external heat flux and coating thickness on the thermal insulation properties of two different intumescent coatings using cone calorimeter and numerical analysis. Fire Mater. 2003, 27, 151.

(6) Sakumoto, Y.; Nagata, J.; Kodaira, A.; Saito, Y. Durability Evaluation of Intumescent Coating for Steel Frames. J. Mater. Civil Eng. 2001, 13, 274.

(7) Wald, F.; et al. Experimental behaviour of a steel structure under natural fire. Fire Safety J. 2006, 41, 509.

(8) Burgess, I.; Olawale, A.; Plank, R. Failure of steel columns in fire. Fire Safety J. 1992, 18, 183.

(9) Noumowe, A.; Siddique, R.; Debicki, G. Permeability of highperformance concrete subjected to elevated temperature $\left(600^{\circ} \mathrm{C}\right)$. Construction Build. Mater. 2009, 23, 1855.

(10) Atienza, J.; Elices, M. Behavior of prestressing steels after a simulated fire: Fire-induced damages. Construction Build. Mater. 2009, 23, 2932.

(11) Schneider, U. Concrete at high temperatures - A general review. Fire Safety J. 1988, 1381, 55.

(12) Tanyildizi, H.; Coskun, A. Performance of lightweight concrete with silica fume after high temperature. Construction Build. Mater. 2008, $22,2269$. 
(13) Bailey, C.; Toh, W. Behaviour of concrete floor slabs at ambient and elevated temperatures. Fire Safety J. 2007, 42, 425.

(14) Baer, D.; Burrows, P.; El-Azab, A. Enhancing coating functionality using nanoscience and nanotechnology. Prog. Org. Coat. 2003, 47, 342.

(15) Wang, Z.; Han, E.; Ke, W. Influence of nano-LDHs on char formation and fire-resistant properties of flame-retardant coating. Prog. Org. Coat. 2005, 53, 29.

(16) Munger, C. Corrosion Prevention by Protective Coatings, third ed; NACE: Houston, TX, 1986.

(17) Leidheiser, H. Corrosion Control by Organic Coatings; NACE: Houston, TX, 1981.

(18) Weldon, D.; Carl, B. Determination of metallic zinc content of inorganic and organic zinc-rich primers by differential scanning calorimetry. J. Coat. Technol. 1997, 69, 45.

(19) Pereyra, A.; Giudice, C. Shaped for performance: the combination of lamellar zinc and mica improves the efficiency of zinc-rich primers. Eur. Coat. J. 2007, 40-45, 9.

(20) Mukherjee, S. Ethyl silicate based zinc rich coatings: A review. Paintindia 1999, 49, 31 .

(21) Parashar, G.; Srivastava, D.; Kumar, P. Ethyl silicate binders for high performance coatings. Prog. Org. Coat. 2001, 42, 1.

(22) Hare, H. Primers for Metal: Fundamental Considerations. J. Protect. Coat. Linings 1998, 15, 48.

(23) Vilche, J.; Bucharsky, E.; Giudice, C. Application of EIS and SEM to evaluate the influence of pigment shape and content in ZRP formulations on the corrosion prevention of naval steel. Corros. Sci. 2002, 44, 1287.

(24) Bastos, A.; Zheludkevich, M.; Ferreira, M. A SVET investigation on the modification of zinc dust reactivity. Prog. Org. Coat. 2008, 63, 282.

(25) Muller, B.; Langenbucher, J. Complete corrosion inhibition of lamellar zinc pigment in aqueous alkaline media. Corros. Sci. 2003, 45, 395.

(26) Dietzel, M. Dissolution of silicates and the stability of polysilicic acid. Geochim. Cosmochim. Acta 2000, 64 (19), 3275.

(27) Papisov, I.; et al. Structural effects in matrix polycondensation of silicic acid. Eur. Polym. J. 1999, 35, 2087.

(28) Tsai, M.; Yang, C.; Huang, P. Effects of seeds concentration on the formation of colloidal silica. Mater. Sci. Eng. 2005, 123, 238.

(29) Tsai, M.; Huang, P.; Wu, W. The study of formation process of colloidal silica. Mater. Res. Bull. 2005, 40, 1609.

(30) Jesionowski, T.; Krysztafkiewicz, A. Properties of highly dispersed silicas precipitated in an organic medium. Dispersion Sci. Technol. 1999, $20,1609$.

(31) Krysztafkiewicz, A.; Jesionowski, T.; Binkowski, S. Precipitated silicas modified with 3-aminopropyltriethoxysilane. Colloids Surf. 2000 173,73 .
(32) Aluru, N.; et al. Nanostructure Studies of the $\mathrm{Si}_{-} \mathrm{SiO}_{2}$ Interface. Handbook of Nanoscience, Engineering and Technology; Gooddard, Brenner, Lyshevski, Iafrate, Ed.; CRC Press.: Washington D.C., 2003; Chapter 11.2.

(33) Gardner, H.; Sward, G. Paint Testing Manual; ASTM STP 500, ASTM: West Conshohocken, PA, 1972; Chapter 6.1.

(34) Giudice, C.; Pereyra, A. Manual Producción de Pinturas; Sater, Ed.; Sociedad Argentina de Tecnólogos en Recubrimientos: Argentina, 2007; p 29.

(35) Giudice, C.; Pereyra, A. Manual Producción de Pinturas; Sater, Ed.; Sociedad Argentina de Tecnólogos en Recubrimientos: Argentina, 2007; p 53.

(36) Giudice, C.; Benítez, J. Rheology of pigment dispersion during paint manufacture. Pitture e Vernici 1994, 70 (11), 33.

(37) Giudice, C.; Benítez, J. Optimising the corrosion protective abilities of lamellar micaceous iron oxide containing primers. Anticorros. Methods Mater. 2000, 47 (4), 226.

(38) Giudice, C.; Benítez, J. $6^{\circ}$ Congresso Internacional de Tintas; San Pablo, Brasil, 1999; Vol. II, p 493.

(39) Jimeneza, M.; Duquesne, S.; Bourbigota, S. Characterization of the performance of an intumescent fire protective coating. Surf. Coat. Technol. 2006, 201, 979.

(40) Jimenez, M.; Duquesne, M.; Bourbigot, S. Multiscale Experimental Approach for Developing High-Performance Intumescent Coatings. Ind. Eng. Chem. Res. 2006, 45, 4500.

(41) Di Blasi, C.; Branca, C. Mathematical Model for the Nonsteady. Decomposition of Intumescent Coatings. AIChE J. 2001, 47 (10), 2359.

(42) Olcese, T.; Pagella, C. Vitreous fillers in intumescent coatings. Prog. Org. Coat. 1999, 6 (4), 231.

(43) Drysdale, D. Fire Retardant Materials, Horrocks and Price, CRC: USA, 2004; p 378.

(44) Giudice, C., Ed. Manual Biodeterioro de Monumentos Históricos de Iberoamérica; Programa de Ciencia y Tecnología para el Desarrollo (CyTED), Subprograma XV, Red Temática XV-E Preservar, España, 2002; p 18.

(45) Giudice, C. Manual Prevención y Protección del Patrimonio Cultural Iberoamericano de los Efectos del Biodeterioro Ambiental; Programa de Ciencia y Tecnología para el Desarrollo (CyTED), Subprograma XV, Red Temática XV-E Preservar, Argentina, 2002; p 211.

(46) Wake, L. V. J. Oil Col. Chem. Assoc. 1988, 71 (11), 378.

Received for review September 8, 2009 Revised manuscript received January 5, 2010 Accepted January 23, 2010

IE901404S 